\title{
Interações agonísticas e desempenho zootécnico no cultivo de Macrobrachium rosenbergii em Tanques-Rede
}

Para identificar as lesões das interações agonísticas e avaliar o desempenho zootécnico do camarão Macrobrobrachium rosenbergii juvenis $(5,39 \pm 2,13 \mathrm{~g})$ em diferentes densidades, os mesmos foram submetidos ao cultivo em tanques rede, alimentados com ração ( $35 \%$ de proteína bruta) às 7:00 e às 14:00 h, com 10\% de sua biomassa, durante 70 dias. Foram aplicados 5 tratamentos, com 5 repetições cada: D5 - 5 animais/m2; D10 - 10 animais/m2; D15 - 15 animais/m2; D20 - 20 animais/m2 e D25 - 25 animais/m2. Para isso, 25 tanques rede foram distribuídos aleatoriamente em 2 viveiros de alvenaria. Para determinar os parâmetros zootécnicos, biometrias foram realizadas a cada 10 dias. A sobra na bandeja foi retirada após $2 \mathrm{~h}$ de permanência para calcularmos o consumo. No final do experimento as lesões foram verificadas e quantificadas. Os resultados foram analisados através do programa STATISTIC 7.0 (2004). As densidades D5 e D10 apresentaram maior peso médio final, ganho de peso, taxa de crescimento específico, eficiência alimentar, sobrevivência, consumo diário, consumo diário pela manhã e consumo diário à tarde. A quantidade de lesões aumentou com o aumento da densidade de estocagem. A densidade de 10 camarões $/ \mathrm{m}^{2}$ apresentou as melhores condições para obter um melhor desempenho em tanque rede.

\section{Agonistic interactions and zootechnical performance in Macrobrachium rosenbergii Culture in Cages}

\begin{abstract}
To evaluate identify injuries of agonistic interactions the animal and performance of Macrobrachium rosenbergii juveniles (5,39 $\pm 2,13 \mathrm{~g}$ ) in different densities, they were subjected to cultures in cages, fed with balanced ration (35\% crude protein) at 7 am and at 2 pm, at $10 \%$ of their biomass, for 70 days. 5 treatments were applied with 5 replications each: D5 - 5 animals/m2; D10 - 10 animals/m2; D15 - 15 animals/m2; D20 - 20 animals/m2; D25 - 25 animals/m2. To this, were distributed 25 cages randomly in two masonry nurseries. To determine the performance parameters, some samples were taken every 10 days. The remnants in the tray were removed after $2 \mathrm{~h}$ of permanence to calculate intake. The end of the experiment the lesions were verified and quantified. The treatments were analyzed using the STATISTIC 7.0 (2004) program. The densities D5 and D10 had higher average final weight, weight gain, specific growth rate, feed efficiency, survival, daily consumption, the morning daily consumption and evening daily consumption. The population of $10 \mathrm{shrimp} / \mathrm{m}^{2}$ offers optimal performance in cage density and the amount of injuries increased with increasing stocking density.
\end{abstract}

Keywords: Carciniculture; Malayan Shrimp; Stocking; Net Tank; Lesions.

Topic: Uso de Recursos Naturais

Reviewed anonymously in the process of blind peer.
Received: 02/10/2019

Approved: 26/11/2019
Daniele Bezerra dos Santos (iD

Instituto Federal do Rio Grande do Norte, Brasil

http://lattes.cnpq.br/5283796635348667

http://orcid.org/0000-0001-7896-6946

danielebezerra@gmail.com

Priscila Maria Oliveira Campos Medeiros

Instituto Federal do Rio Grande do Norte, Brasil

http://lattes.cnpq.br/6033199741723658

http://orcid.org/0000-0002-9702-8215

prizx@hotmail.com

Vinícius Gabriel da Silva Santana (it)

Universidade Federal do Rio Grande do Norte, Brasil

http://lattes.cnpq.br/5134985293427059

http://orcid.org/0000-0002-9474-1189

umenoventa@hotmail.com
Cibele Soares Pontes (iD)

Instituto Federal do Rio Grande do Norte, Brasil

http://lattes.cnpq.br/3943018673158703

http://orcid.org/0000-0003-1993-0032

cibelepontes.ufrn@yahoo.com.br
Referencing this:

SANTOS, D. B.; MEDEIROS, P. M. O. C.; SANTANA, V. G. S.; PONTES, C. S.. Interações agonísticas e desempenho zootécnico no cultivo de Macrobrachium rosenbergii em Tanques-Rede. Revista Ibero Americana de Ciências Ambientais, v.10, n.6, p.339-347, 2019. DOI: http://doi.org/10.6008/CBPC2179-6858.2019.006.0029 


\section{INTRODUÇÃO}

A carcinicultura de água doce é um dos setores da aquicultura que tem apresentado maior crescimento no mundo (NEW et al., 2010; MURALISANKAR et al., 2014; FAO, 2018). Os dados mais atuais da produção mundial do camarão Macrobrachium rosenbergii foi de 216.847 toneladas (FAO, 2016). Segundo Valenti et al. (2004) o cultivo de camarões de água doce no Brasil está centralizado na espécie exótica Macrobrachium rosenbergii, uma das mais utilizadas para fins comerciais no mundo. Determinar a densidade de estocagem ideal para o cultivo dessa espécie pode ser um fator-chave para o sucesso do cultivo, tanto por razões econômicas, quanto da busca pelo bem-estar dos animais.

A densidade de estocagem apresenta grande influência sobre a produção dos camarões em cativeiro (JACKSON et al., 1998), podendo atuar sobre o crescimento, sobrevivência e interação dos camarões em função da competição por recursos vitais, interferindo em seu comportamento social e agonístico (VALENTI et al., 2000). Alguns autores apontaram uma relação inversa entre a densidade populacional e o desempenho de camarões de água doce (ARANEDA et al., 2008; MARQUES et al., 2000; TIDWELL et al., 1999; VALENTI et al., 1993).

Na Malásia, os tanques de engorda para monocultivo de $M$. rosenbergii são geralmente estocados com 4 a 10 pós-larvas ou juvenis/m² (VALENTI et al., 2004). Um aumento da densidade de estocagem no cultivo dessa espécie poderá ocasionar maior número de lesões, de canibalismo e de mortalidade, o que deve ser evitado em função da manutenção da qualidade do produto a ser despescado.

Um dos entraves para o desenvolvimento do cultivo do $M$. rosenbergii é o comportamento agressivo dessa espécie, com altos níveis de canibalismo, também pela mortalidade ou pelas baixas taxas de crescimento apresentadas pelos animais subordinados em função dos confrontos agonísticos. Os camarões desse gênero apresentam o 2ㅇ par de pereiópodos bem desenvolvido, considerado como estrutura primordial na predação e na agressão inter e intraespecífica, sendo aquelas essenciais não somente para a defesa, mas também para o ataque e a aquisição de recursos limitantes. Alguns trabalhos relatam o comportamento agonístico desse crustáceo (PEEBLES, 1979; KARPLUS et al., 1992; KARPLUS, 2005; SILVA et al., 2014; SANTOS et al., 2016; SANTOS et al., 2018), mas poucos falam das partes do corpo do animal que são lesionadas devido a conflitos ocorridos por competição de recursos.

A carcinicultura em tanques rede está sendo considerada como uma alternativa para a aquicultura, que pode vir a ser um meio sustentável de cultivar camarões e uma fonte de renda para comunidades. Estudos para desenvolver tecnologias para a utilização deste sistema são mais frequentes em carcinicultura marinha (WASIELESKY et al., 2001; KRUMMENAUER et al., 2006; ZARAIN-HERZBERG et al., 2006; 2010), havendo pouca informação sobre o uso de tanques-rede em cultivo de camarão de água doce (CUVINARALARET et al., 2007; LANGER et al., 2011; MARQUES et al., 2000; MARQUES et al., 2011). O objetivo deste trabalho foi avaliar o desempenho zootécnico e identificar as lesões provenientes de interações agonísticas do camarão Macrobrachium rosenbergii de acordo com as diferentes densidades em tanques rede. 


\section{MATERIAIS E MÉTODOS}

O experimento foi realizado na Escola Agrícola de Jundiaí - Universidade Federal do Rio Grande do Norte (UFRN), distrito de Macaíba, no Rio Grande do Norte, na Estação de Aquicultura Professor Sebastião Monte. A fase experimental durou setenta dias. As pós-larvas (PL's) de M. rosenbergii foram obtidas a partir de larvicultura experimental realizada no Laboratório de Produção de Organismos Aquáticos do Departamento de Oceanografia e Limnologia da UFRN - Natal, e levadas para a Estação de Aquicultura Professor Sebastião Monte (EAJ/UFRN), onde permaneceram em tanque berçário por 53 dias. Para o desenvolvimento do experimento, utilizou-se dois viveiros retangulares de alvenaria $\left(86,4 \mathrm{~m}^{2}\right)$ com profundidade útil de 1,20 m. Uma semana antes do povoamento a água dos viveiros foi fertilizada com Ureia (2 kg/ha) e Superfosfato Triplo ( 8 kg/ha) (BOYD et al., 2010). Os camarões foram pesados em balança digital e transferidos para 25 tanques-rede distribuídos aleatoriamente (sorteio) nos dois viveiros já preparados (figura 1).

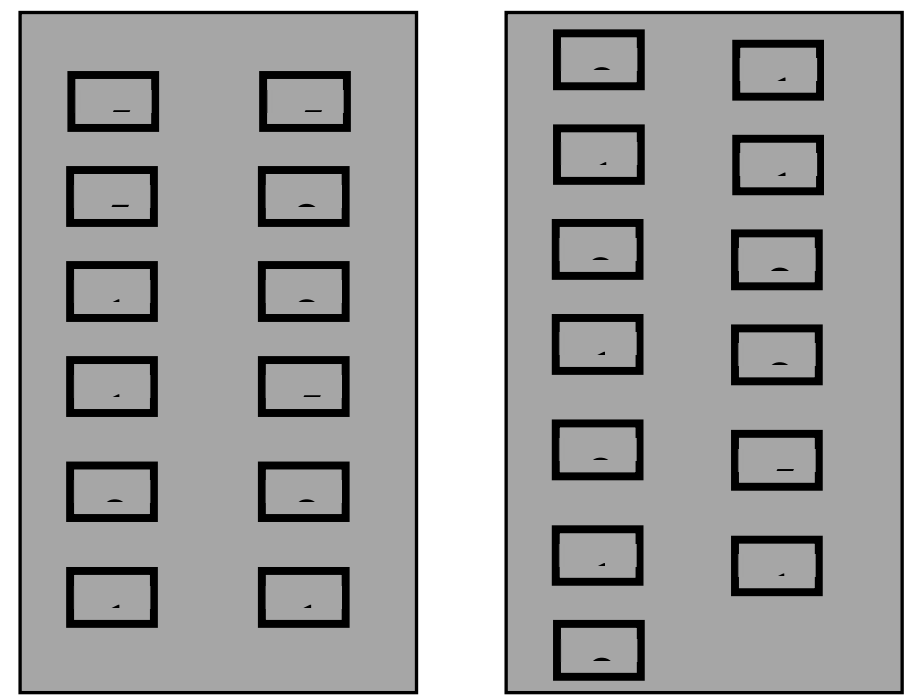

Figura 1: Layout dos 25 tanques rede, distribuídos aleatoriamente em dois viveiros, com os camarões $M$. rosenbergii submetidos às densidades de estocagem com 5, 10, 15, 20 e 25 camarões/m², com cinco repetições.

Os tanques rede possuíam $1 \mathrm{~m}^{3}$, com malha de $5 \mathrm{~mm}$ entre nós. Os animais permaneceram em adaptação por quinze dias antes do início da coleta de dados. A fase experimental teve início quando os camarões $M$. rosenbergii estavam com peso médio de 5,39 ( $\pm 2,13 \mathrm{~g})$, submetidos aos seguintes tratamentos, com 5 repetições cada: a) D5 - 5 animais $/ \mathrm{m}^{2}$; b) D10 - 10 animais/m²; c) D15 - 15 animais/m²; d) D20 - 20 animais/m²; e) D25 - 25 animais $/ \mathrm{m}^{2}$. Durante o cultivo, os animais foram alimentados com ração peletizada para camarão com $10 \%$ da sua biomassa, com 35\% de proteína bruta, ofertada em bandejas de alimentação. A oferta se deu no parcelamento de duas vezes ao dia, nos horários de 7:00 h e 14:00 h.

Para análise do desempenho zootécnico e produtividade, a cada 10 dias eram capturados aleatoriamente 5 camarões de cada tanque-rede para a realização das biometrias. 0 ganho de peso foi mensurado ao final do experimento (KURESHY et al., 2002), e serviu de base para o cálculo da taxa de crescimento específico (TCE) (WU et al., 2002):

Ganho de Peso $(g)=P_{f}-P_{i}$ 
$\operatorname{TCE}\left(\% \mathrm{dia}^{-1}\right)=\left[\operatorname{Ln}\left(P_{f}\right)-\operatorname{Ln}\left(P_{i}\right)\right] \times 100 t^{-1}$

(Em que: $P_{i}=$ Peso inicial; $P_{f}=$ Peso final; $L n=$ Logaritmo; $t=$ tempo de experimento).

Para determinar o peso da sobra da ração e o percentual de umidade, utilizamos a metodologia de Santos et al. (2011). O valor obtido (48\% de umidade) foi subtraído do peso úmido das sobras da ração. A partir dos valores obtidos da sobra da ração, calculamos o consumo aparente da ração pela diferença entre alimento oferecido e a sua sobra na bandeja retirada após $2 \mathrm{~h}$ de permanência, baseado no trabalho de Pontes et al. (2005), que verificaram que a ração perde a atratividade após esse tempo. Posteriormente, foi calculado a eficiência alimentar (KURESHY et al., 2002).

Consumo $=$ Ração ofertada - Sobra

Eficiência alimentar $=\left(P_{f}-P_{i}\right)$ consumo ${ }^{-1}\left(\right.$ Em que: $P_{i}=$ Peso inicial; $P_{f}=$ Peso final $)$.

No final do experimento foram verificadas as ocorrências de indivíduos mortos e seu número foi registrado para o cálculo da taxa final sobrevivência (definida por BAUTISTA-TERUEL et al., 2003).

Sobrevivência $(\%)=N_{f} \times 100 / N_{i}$ (Em que: $N_{i}=$ Número inicial; $N_{f}=$ Número final).

A água das unidades experimentais foi verificada diariamente através dos parâmetros: $\mathrm{pH}(\mathrm{pH}-$ metro), oxigênio dissolvido (oxímetro), temperatura (termômetro de eletrodo). Já os parâmetros nitrito e amônia foram analisados semanalmente através do método colorimétrico simplificado. Para identificar as lesões das interações agonísticas de juvenis $M$. rosenbergii submetidos a cultivo em tanques rede, ao final do experimento foi verificada a frequência de lesões nos camarões de acordo com as densidades estudadas. Foram verificadas pereiópodos lesionados, pereiópodos amputados, pleópodos lesionados, pleópodos amputados, antenas e antênulas lesionadas, antenas e antênulas amputadas, telson e urópodo lesionado, telson e urópodo amputado, cefalotórax lesionado, olhos amputados, segundo pereiópodo lesionado, segundo pereiópodo amputado, rostro lesioado e rostro amputado. Apenas camarões sem quaisquer ferimentos visíveis foram utilizados neste experimento.

Para realização das análises estatísticas foi utilizado o programa STATISTIC 7.0 (2004). Os dados foram analisados se utilizando o teste Anova One-Way para as variáveis que foram considerados normais (teste de normalidade Shapiro-Wilks) e homocedásticas (Levene's test). Para as variáveis que não apresentaram normalidade e homocedasticidade, aplicou-se o teste não-paramétrico Kruskal-Wallis. Foi aplicado o Wilcoxon Matched Pairs Test para determinar a significância entre o consumo no período da manhã e da tarde. Para verificar a existência de diferença significativa na frequência de lesões entre as diferentes densidades, utilizou-se o teste do qui-quadrado $\left(\mathrm{X}^{2}\right)$. O nível de significância adotado foi $p<0,05$.

\section{RESULTADOS E DISCUSSÃO}

Não foram registradas diferenças significativas quanto ao peso inicial dos camarões componentes das diferentes densidades $(p=0,3654)$. Durante a pesquisa, a temperatura $(27,39 \pm 0,87), \mathrm{pH}(7,89 \pm 0,49)$ e oxigênio $(7,01 \pm 0,94 \mathrm{mg} / \mathrm{L})$ da água dos viveiros para o cultivo de $M$. rosenbergii permaneceram dentro dos parâmetros aceitáveis segundo Boyd et al. (2010), pois a faixa ideal para temperatura fica entre 25 e 32 ㄷ, 
pH entre 7 e 8,5 e oxigênio dissolvido entre 3 e $7 \mathrm{mg} / \mathrm{L}$. Os teores de nitrito $\left(\mathrm{NO}_{2}\right)$ e da amônia $\left(\mathrm{NH}_{4}{ }^{+}\right)$foram sempre inferiores a $0,05 \mathrm{mg} / \mathrm{L}$.

A elevação da densidade de estocagem dos animais confinados em tanques rede afetou significativamente o peso médio final (ANOVA, $p<0,05$ ), o ganho de peso (ANOVA, $p<0,05$ ) e a taxa de crescimento específico (Kruskal-Wallis, $\mathrm{H}=11,55692, \mathrm{~N}=25, \mathrm{p}<0,05$ ), embora a eficiência alimentar não tenha sido afetada (ANOVA, $p=0,05$ ) como também a sobrevivência (Kruskal-Wallis, $H=7,552078, N=25$, p> 0,05). Cuvin-Aralaret et al. (2007), observaram uma variação no crescimento de 26,3 para $14,3 \mathrm{~g}$ com densidade de estocagem entre 15 a 90 camarões $/ \mathrm{m}^{2}$ em um experimento com $M$. rosenbergi juvenil $(0,4 \mathrm{~g})$ no sistema de cultivo com gaiola $(2,5 \times 1 \times 1 \mathrm{~m})$ em um lago nas Filipinas, por 5 meses.

Marques et al. (2000) observaram que $M$. rosenbergiii cultivados em tanques rede em densidades mais elevadas $\left(100,200,300,400,600\right.$ e $\left.800 \mathrm{PLs} / \mathrm{m}^{2}\right)$ e peso inicial menor $(0,053 \pm 0,009 \mathrm{~g})$ também não apresentaram diferenças na sua sobrevivência. Esses autores acentuam que o efeito da densidade de estocagem na sobrevivência foi menor que sobre o crescimento, hipnotizando que menores densidades reduzem a competição intraespecífica entre os animais. Langer et al. (2011) estudaram o efeito de diferentes densidades de estocagem $\left(5,10,15\right.$ e 20 camarões $\left./ \mathrm{m}^{2}\right)$ no crescimento e sobrevivência com pós-larvas do camarão $M$. rosenbergii com peso médio de 0,114 g e cultivadas durante um período de 49 dias em condições de laboratório, o desempenho zootécnico dos camarões diminuiu com o aumento densidade de estocagem e a densidade de 5 camarões $/ \mathrm{m}^{2}$ foi considerada ideal.

Nesta pesquisa, a taxa de crescimento específico de $M$. rosenbergii se reduziu à medida que a densidade de estocagem aumentou. $\mathrm{O}$ baixo crescimento dos animais nas densidades mais elevadas pode ter sido causado pela competição por espaço e por ração. De acordo com Valenti et al. (1993), o gasto de energia decorrente da disputa e defesa de um território torna-se maior em densidades mais elevadas, podendo contribuir para uma diminuição na taxa de crescimento.

A presença de alimento em abundância não excluiu a competição por este recurso, uma vez que os camarões maiores podem impedir o acesso dos menores à alimentação (KARPLUS et al., 1992), desta forma a dominância e territorialidade de alguns indivíduos pode interferir diretamente no crescimento de outros. O peso médio final, o ganho de peso e a taxa de crescimento específico foram mais elevados nas menores densidades de estocagem (D5 e D10) (Figura 2 - A, B e C). Apesar disto, os valores médios de eficiência alimentar e de sobrevivência não apresentaram diferenças com relação aos tratamentos aplicados (Figura 2 - D e E).

Podemos afirmar que $M$. rosenbergii foi mais eficiente para converter a ração consumida em peso vivo nas densidades mais baixas, atestando sua potencialidade para criação em baixas densidades, uma prática considerada ambientalmente saudável. Foram observadas diferenças no consumo diário da ração entre as ofertas da manhã e da tarde $(p<0,05)$, bem como entre os tratamentos (ANOVA, $p<0,05$ ) e o consumo diário no turno da manhã (ANOVA, $p<0,05$ ), mas não foi registrada diferença significativa para consumo diário no turno da tarde (Kruskal-Wallis, $\mathrm{H}=9,216000, \mathrm{~N}=25, \mathrm{p}>0,05$ ) nos diferentes tratamentos (Figura 2 - F e G). 


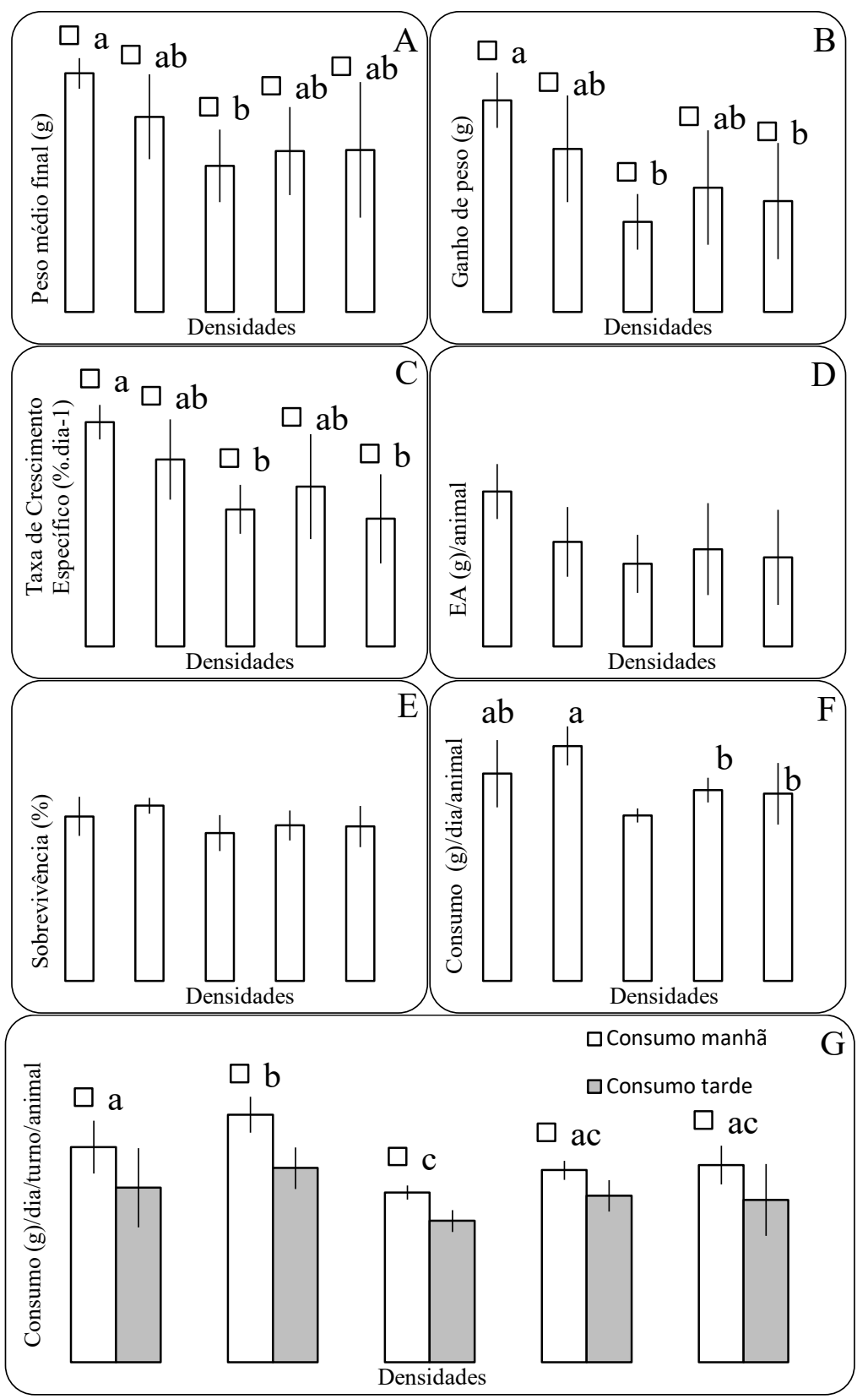

Figura 2: Peso médio final (g) (A), ganho de peso (g) (B), taxa de crescimento específico (C), eficiência alimentar (D), sobrevivência (E), consumo diário(g)/animal (F), consumo diário (g)/turno/animal (G) dos camarões $M$. rosenbergii.

Letras diferentes representam diferença significativa entre os tratamentos.

O consumo diário no turno da manhã por indivíduo foi maior do que no turno da tarde (figura 2 - G), possivelmente isto aconteceu porque o intervalo (17 h) entre as refeições da tarde (14 h) e da manhã (7 h) era maior do que o intervalo ( $7 \mathrm{~h}$ ) entre as refeições da manhã $(7 \mathrm{~h})$ e da tarde $(14 \mathrm{~h})$, no entanto o animal comia mais no turno da manhã pelo jejum ser mais prolongado, pois quanto mais tempo sem alimento mais fome irá sentir.

Além disso, foi observado que quase sempre sobrava ração nas bandejas, ou seja, a ração era pouco consumida, Preto et al. (2008) também observaram que a ração na bandeja era praticamente pouco consumida pelo camarão-da-Amazônia. Provavelmente, este fato ocorreu devido ao comportamento territorial e agressivo do M. rosenbergii (KARPLUS et al., 1992; KARPLUS, 2005; SANTOS et al., 2016; SANTOS et al., 2018). 
Pouco se sabe sobre como a densidade de estocagem afeta os camarões $M$. rosenbergii mantidos em tanques-rede e não houve estudos que quantificassem a quantidade ideal de animais por $\mathrm{m}^{2}$ para a engorda desses camarões no que diz respeito ao desempenho zootécnico. A avaliação da incidência e quantidade de lesões no corpo dos animais ao final do cultivo pode funcionar como um indicativo da ocorrência da agressividade desses animais em função do aumento da densidade de estocagem, trazendo dados referentes ao bem-estar desse animal, que, uma vez confrontados com os dados de desempenho zootécnico, poderá nos indicar quais as melhores densidades a serem praticadas.

Os danos ocasionados por confrontos agonísticos não necessariamente causam mortes dos animais (BRUGIOLO et al., 2007), pois percebemos que apesar dos danos encontradas no corpo dos camarões, a mortalidade foi baixa (Figura 2 E). Observamos que as partes do corpo dos camarões mais atingidas foram respectivamente: pereiópodos, pleópodos, antenas e antênulas, urópodo e télson, 2o pereiópodos, rostro, abdômen e o cefalotórax (Figura 3). Brugiolo et al. (2007) verificaram que as partes atingidas no corpo dos animais foram pereópodes, pleópodes, rostros e/ou abdômen.

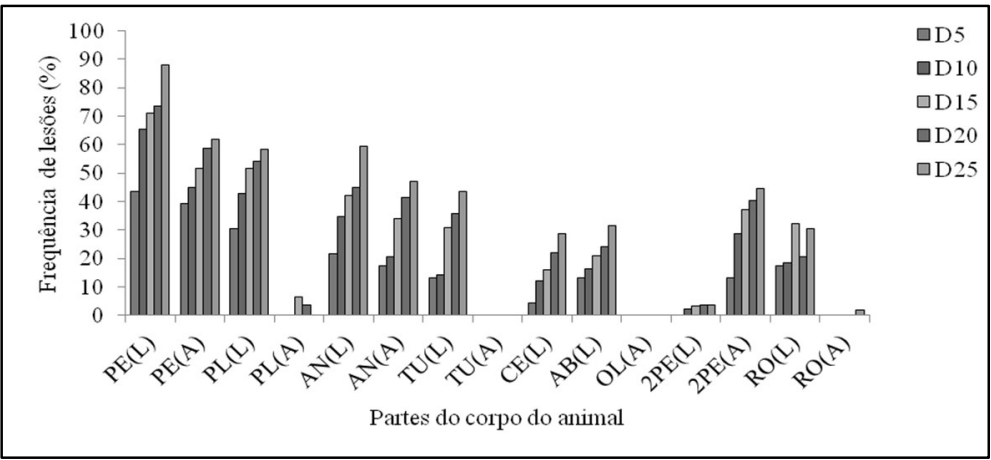

Figura 3: Frequência em porcentagem dos pereiópodos lesionados $(P E(L))$, pereiópodos amputados $(P E(A))$, pleópodos lesionados $(P L(L))$, pleópodos amputados $(P L(A))$, antenas e antênulas lesionadas $(A N(L))$, antenas e antênulas amputadas $(A N(A))$, telson e urópodo lesionado $(T U(L))$, telson e urópodo amputado $(T U(A))$, cefalotórax lesionado $(C E(L))$, olhos amputados $(\mathrm{OL}(A))$, segundo pereiópodo lesionado $(2 \mathrm{PE}(\mathrm{L}))$, segundo pereiópodo amputado $(2 \mathrm{PE}(\mathrm{A}))$, rostro lesioado $(R O(L))$ e rostro amputado $(R O(A))$ nas densidades D5 (5 camarões $\left./ \mathrm{m}^{2}\right)$, D10 (10 camarões $\left./ \mathrm{m}^{2}\right), \mathrm{D} 15$

(15 camarões $\left./ \mathrm{m}^{2}\right)$, D20 (20 camarões $/ \mathrm{m}^{2}$ ) e D25 (25 camarões $/ \mathrm{m}^{2}$ ).

A frequência de lesões foi maior do que amputações, sendo o 2o pereiópodo mais amputado do que lesionado e a proporção de quelípodos amputados aumentou com o aumento da densidade de estocagem (Figura 3). Segundo Pinheiro et al. (1998) é muito comum que o $2^{\circ}$ par de pereiópodos seja perdido por ocasião de combate e durante o manejo praticado pelo homem, em condições de cultivo.

Não foi registrada diferença significativa para os pereiópodos lesionados ( $p>0,05)$, para télson e urópodo amputado $(p>0,05)$, para o segundo pereiópodo lesionado $(p>0,05)$, para rostro lesionado ( $p>$ $0,05)$ e rostro amputado $(p=0,5)$ entre as diferentes densidades testadas. O número de lesões e amputações foi mais alto para os pereiópodos, pleópodos, antenas e antênulas, que são regiões mais frágeis, do que o abdômen e o cefalotórax que são partes relativamente mais robustas (Figura 3). O comportamento agressivo também é frequente em lagostas e geralmente resulta em ferimentos em apêndices do corpo. Kouba et al. (2011) sugere que a alta incidência das lesões nas antenas seja devido a sua estrutura delicada e sua posição exposta, o que as torna vulneráveis a danos. 
A importância dos pereiópodos, pleópodos, antenas e antênulas são bem conhecidas, os três últimos pares de pereiópodos servem como patas locomotoras, os pleópodos são responsáveis pela natação do animal, nas fêmeas adultas também servem para a fixação e incubação dos ovos, enquanto que, nos machos o segundo par é transformado em estruturas auxiliares para copulação, as antenas e antênulas são considerados apêndices sensoriais (PINHEIRO et al., 1998). Corroborando com nossos resultados, Savolainen et al. (2004) afirma que a frequência de ataques por membros da mesma espécie irá aumentar em função do aumento da densidade de estocagem, fazendo com que haja uma incidência maior de lesões em densidades mais elevadas. Portanto, as partes lesionadas e amputadas tiveram menores incidências nas densidades mais baixas, apontando este como um importante fator no bem-estar de $M$. rosenbergii em condições de cultivo, bem como na preservação da qualidade do produto final que consumidor exige.

\section{CONCLUSÕES}

Dentre as densidades de estocagem que os camarões tiveram melhores desempenho, a população de 10 camarões $/ \mathrm{m}^{2}$ foi a que obteve melhores índices zootécnicos. A quantidade de lesões aumentou com o aumento da densidade de estocagem. As partes do corpo dos camarões mais atingidas foram respectivamente: pereiópodos, pleópodos, antenas e antênulas.

\section{REFERÊNCIAS}

ARANEDA, M.; PÉREZ, E. P.; GASCA-LEYVA, E.. White shrimp Penaeus vannamei culture in freshwater at three densities: condition state based on length and weight. Aquaculture, v.283, p.13-18, 2008.

BAUTISTA-TERUEL, M. N.; EUSEBIO, P. S.; WELSH, T. P.. Utilization of feed pea, Pisum sativum, meal as a protein source in practical diets for juvenile tiger shrimp, Penaeus monodon. Aquaculture, v.225, p.121-131, 2003.

BOYD, C. E.; ZIMMERMANN, S.. Grow-out Systems-Water Quality and Soil Management. In: NEW, M. B.; VALENTI, W. C.; TIDWELL, J. H.; D'ABRAMO, L. R.; KUTTY, M. N.. Freshwater Prawns: Biology and Farming. Oxford: WileyBlackwell, p. 239-255, 2010.

BRUGIOLO, S. S. S.; BARBOSA, J. M.; BLAZQUEZ, F. J. H.; NASCIMENTO, P. A. M.. Canibalismo em fêmeas de Macrobrachium rosenbergii ( De Man, 1879) (Crustacea, Palaemonidae): efeito da retirada das quelas. Revista Portuguesa de Ciências Veterinárias, v.102, p.153-157, 2007.

CUVIN-ARALAR, M. L. A; ARALAR, E. V.; LARON, M.; ROSARIO, W.. Culture of Macrobrachium rosenbergii (De Man 1879) in experimental cages in a freshwater eutrophic lake at different stocking densities. Aquaculture Research, v.38, p.288-294, 2007.

FAO. Food and Agriculture Organization of the United Nations. Fishery and Aquaculture Statistics 2014. Rome: FAO, 2016.

FAO. Food and Agriculture Organization of the United Nations. The State of World Fisheries and Aquaculture:
Meeting the Sustainable Development Goals. Rome: FAO, 2018.

JACKSON, C. J.; WANG, Y. G.. Modelling growth rate of Penaeus monodon Fabricius in intensively managed ponds: effects of temperature, pond age and stocking density. Aquaculture Research, v.29, p.27-36, 1998.

KARPLUS, I.; HULATA, G.; OVADIA, D.; JAFFE, R.. Social control of growth in Macrobrachium rosenbergii III. The role of claws in bull-runt interactions. Aquaculture, v.105, p.281296, 1992.

KARPLUS, I.. Social control of growth in Macrobrachium rosenbergii (De Man): a review and prospects for future research. Aquaculture Research, v.36, p.238-254, 2005.

KRUMMENAUER, D.; WASIELESKY JUNIOR, W.; CAVALLI, R. O.; PEIXOTO, S.; ZOGBI, P. B.. Viabilidade do cultivo do camarão-rosa Farfantepenaeus paulensis (Crustácea: Decapoda) em gaiolas sob diferentes densidades durante o outono no Sul do Brasil. Ciência Rural, v.36, p.252-257, 2006.

KOUBA, A.; BUŘIČ, M.; POLICAR, T.; KOZÁK, P.. Evaluation of body appendage injuries to juvenile signal crayfish (Pacifastacus leniusculus): relationships and consequences. Knowledge and Management of Aquatic Ecosystems, n.401, p.4, 2011.

KURESHY, N.; DAVIS, D. A.. Protein requirement for maintenance and maximum weight gain for the Pacific white shrimp, Litopenaeus vannamei. Aquaculture, n.204, p.125143, 2002. 
LANGER, S.; KARLOPIA, S. K.; BAKHTIYAR, Y.. Effect of different stocking densities on the growth and survival of freshwater prawn, Macrobrachium rosenbergii under laboratory conditions in Jammu. International Journal of Fisheries and Aquaculture Sciences, v.1, n.1, p.19-25, 2011.

MARQUES, A.; LOMBARDI, J. V.; BOOCK, M. V.. Stocking densities for nursery phase culture of the freshwater prawn Macrobrachium rosenbergii in cages. Aquaculture, n.187, p.127-132, 2000.

NEW, M. B.. History and global status of freshwater prawn farming. In: NEW, M. B.; VALENTI, W. C.. Freshwater Prawn Farming: The Farming of Macrobrachium rosenbergii. Londres, Blackwells, 2000. p.1-11.

NEW, M. B.. Freshwater prawn farming: global status, recent research and glace at the future. Aquaculture Research, n.36, p.210-230, 2005.

PEEBLES, J. B.. The roles of prior residence and relative size in competition for shelter by the Malaysian prawn, Macrobrachium rosenbergii. Fishery Bulletin, n.76, p.173180, 1979.

PINHEIRO, M. A. A.; HEBLING, N. J.. Biologia de Macrobrachium rosenbergii (De Man, 1879). In: VALENTI, W. C.. Carcinicultura de água doce. Tecnologia para produção de camarões. Instituto Brasileiro do Meio Ambiente e dos Recursos Naturais Renováveis, Brasília, 1998. p.21 -46.

PONTES, C. S.; ARRUDA, M. F.. Acesso ao alimento artificial e enchimento do trato digestivo de juvenis do camarão marinho Litopenaeus vannamei (Boone) (Crustacea, Decapoda, Penaeidae) durante as fases clara e escura do período de 24 horas. Revista Brasileira de Zoologia, n.22, p.1039-1043, 2005.

PRETO, B. L.; PIZZATO, G. M.; VALENTI, W. C.. Uso de bandejas de alimentação na fase de engorda do camarão-daamazônia, Macrobrachium amazonicum (Heller, 1862). Boletim do Instituto de Pesca, v.34, p.125-130, 2008.

SANTOS, D. B.; PONTES, C. S.; FREIRE, F. A. M.; BESSA JUNIOR, A. P. . Efeito do tipo de sedimento na eficiência alimentar, crescimento e sobrevivência de Litopenaeus vannamei (Boone, 1931). Acta Scientiarum. Biological Sciences, v.33, n.4, p.369-375, 2011. DOI: http://doi.org/10.4025/actascibiolsci.v33i4.6134

SANTOS, D. B.; ALMEIDA, L. M.; MOURA, E. E. S.; ARRUDA, M. F.; PONTES, C. S.. Behavior activities of Macrobrachium rosenbergii (De Man, 1879) in monosex and mixed populations, in the laboratory. Journal of Animal Behaviour and Biometeorology, v.6, n.2, p.33-40, 2018. DOI: http://doi.org/10.31893/2318-1265jabb.v6n2p33-40

SANTOS, D. B.; PONTES, C. S.. Behavioral repertoire of the giant freshwater prawn Macrobrachium rosenbergii (De Man, 1879) in laboratory. Journal of Animal Behaviour and
Biometeorology, v.4, n.4, p.109-115, 2016.

DOI: http://doi.org/10.14269/2318-1265/jabb.v4n4p109$\underline{115}$

SAVOLAINEN, R.; RUOHONEN, K.; RAILO, E.. Effect of stocking density on growth, survival and cheliped injuries of stage 2 juvenile signal crayfish Pasifastacus leniusculus Dana. Aquaculture Research, n.231, p.237-248, 2004. DOI: http://doi.org/10.1016/j.aquaculture.2003.09.045

SILVA, P. F.; ARRUDA, M. F.. Social status and individual behavioral differences in juvenile Macrobrachium rosenbergii. Marine and Freshwater Behaviour and Physiology, v.8, p.1-11, 2014.

TIDWELL, J. H.; COYLE, S.; WEIBEL, C.; EVANS, J.. Effects and interactions of stocking density and added substrate on production and population structure of freshwater prawns Macrobrachium rosenbergii. Journal World Aquaculture. Soc., v.30, n.2, p.174-179, 1999.

VALENTI, W. C.; MELLO, J. T. C.; CASTAGNOLLI, N.. The effect of stocking density on Macrobrachium rosenbergii (De Man) growth curves in earthen ponds (Crustacea, Palaemonidae). Revista Brasileira de Zoologia, n.10, p.427-438, 1993.

VALENTI, W. C.; NEW, M. B.. Grow-out systems: monoculture. In: NEW, M. B.; VALENTI, W. C.. Freshwater prawn culture: the farming of Macrobrachium rosenbergii. Oxford: Blackwell Science Limited, 2000. p.157-176.

VALENTI, W. C.. Situação Atual, perspectivas e novas tecnologias para produção de camarões de água doce. In: CONGRESSO DE AQUICULTURA; SIMPÓSIO BRASILEIRO DE AQUICULTURA, 12; CAMPUS II DA ESCOLA DE AGRONOMIA. Anais. Goiânia: ABRAQ, 2002. p.99-106.

VALENTI, W. C.: MORAES-RIODADES, P. M. C.. Freshwater prawn farming in Brazil. Global Aquaculture Advocate, Saint Louis, v.7, n.4, p.52-53, 2004.

WASIELESKY, W.; POERSCH, L. H.; JENSEN, L.; BIANCHINI, A. Effect of stocking density on growth of pen reared pink shimp Farfantepenaeus paulensis (Pérez Farfante, 1967) (Crustacea, Penaeidae). Náuplius, v.9, p.163-167, 2001.

WU, L.; DONG, S.. Effects of protein restriction with subsequent realimentation on growth performance of juvenile Chinese shrimp (Fenneropenaeus chinensis). Aquaculture, v.210, n.1-4, p.343-358, 2002.

ZARAIN-HERZBERG, M.; CAMPA-CÓRDOVA, A. I.; CAVALLI, R. O.. Biological viability of producing white shrimp Litopenaeus vannamei in seawater floating cages. Aquaculture, n.259, p.283-289, 2006.

ZARAIN-HERZBERG, M.; FRAGA, I.; HERNANDEZ-LLAMAS, A. Advances in intensifying the cultivation of the shrimp Litopenaeus vannamei in floating cages. Aquaculture, n.300, p.87-92, 2010.

A CBPC - Companhia Brasileira de Produção Científica (CNPJ: 11.221.422/0001-03) detém os direitos materiais desta publicação. Os direitos referem-se à publicação do trabalho em qualquer parte do mundo, incluindo os direitos às renovações, expansões e disseminações da contribuição, bem como outros direitos subsidiários. Todos os trabalhos publicados eletronicamente poderão posteriormente ser publicados em coletâneas impressas sob coordenação da Sustenere Publishing, da Companhia Brasileira de Produção Científica e seus parceiros autorizados. Os (as) autores (as) preservam os direitos autorais, mas não têm permissão para a publicação da contribuição em outro meio, impresso ou digital, em português ou em tradução. 